\title{
Association between mortality and age among mechanically ventilated COVID-19 patients: a Japanese nationwide COVID-19 database study
}

Chie Tanaka', Takashi Tagami ${ }^{2,3^{*}}$, Fumihiko Nakayama', Saori Kudo ${ }^{1}$, Akiko Takehara', Reo Fukuda', Junya Kaneko ${ }^{1}$, Yoshito Ishiki ${ }^{1}$, Shin Sato ${ }^{1}$, Ami Shibata ${ }^{1}$, Masamune Kuno ${ }^{1}$, Kyoko Unemoto ${ }^{1}$, Masayuki Hojo ${ }^{7}$, Tetsuya Mizoue 6 , Yusuke Asai ${ }^{5}$, Setsuko Suzuki ${ }^{4}$ and Norio Ohmagari, ${ }^{4,5}$

\begin{abstract}
Background: Only a few studies have reported the association between age and mortality in COVID-19 patients who require invasive mechanical ventilation (IMV). We aimed to evaluate the effect of age on COVID-19-related mortality among patients undergoing IMV therapy.

Methods: This cohort study was conducted using the COVID-19 Registry Japan database, a nationwide multi-centre study of hospitalized patients with laboratory-confirmed COVID-19. Of all 33,808 cases registered between 1 January 2020 to 28 February 2021, we analysed 1555 patients who had undergone IMV. We evaluated mortality rates between age groups using multivariable regression analysis after adjusting for known potential components, such as withinhospital clustering, comorbidities, steroid use, medication for COVID-19, and vital signs on admission, using generalized estimation equation.
\end{abstract}

Results: By age group, the mortality rates in the IMV group were $8.6 \%, 20.7 \%, 34.9 \%, 49.7 \%$ and $83.3 \%$ for patients in their 50s, 60s, 70s, 80s, and 90s, respectively. Multivariable analysis showed that compared with those for patients aged $<60$ years, the odds ratios (95\% confidence interval) of death were 2.6 (1.6-4.1), 6.9 (4.2-11.3), 13.2 (7.2-24.1), 92.6 (16.7-515.0) for patients in their 60s, 70s, 80s, and 90s, respectively.

Conclusions: In this cohort study, age had a great effect on mortality in COVID-19 patients undergoing IMV, after adjusting for variables independently associated with mortality. This study suggested that age was associated with higher mortality and that preventing progression to severe COVID-19 in elderly patients may be a great public health issue.

Keywords: COVID-19, Age, Mechanical ventilation, Mortality

*Correspondence: t-tagami@nms.ac.jp

2 Department of Emergency and Critical Care Medicine, Nippon Medical School Musashikosugi Hospital, 1-396 Kosugimachi, Nakahara-ku, Kawasaki, Kanagawa 211-8533, Japan

Full list of author information is available at the end of the article

\section{Background}

In December 2019, the first case of the novel coronavirus disease 2019 (COVID-19), caused by severe acute respiratory syndrome coronavirus 2 (SARS-CoV-2), was reported in Wuhan, China [1]. The first COVID-19 case in Japan was reported on 16 January, 2020, and the World Health Organization (WHO) declared COVID19 a pandemic on 11 March 2020 [2, 3]. Currently, the
Springer Open

(c) The Author(s) 2021. Open Access This article is licensed under a Creative Commons Attribution 4.0 International License, which permits use, sharing, adaptation, distribution and reproduction in any medium or format, as long as you give appropriate credit to the original author(s) and the source, provide a link to the Creative Commons licence, and indicate if changes were made. The images or other third party material in this article are included in the article's Creative Commons licence, unless indicated otherwise in a credit line to the material. If material is not included in the article's Creative Commons licence and your intended use is not permitted by statutory regulation or exceeds the permitted use, you will need to obtain permission directly from the copyright holder. To view a copy of this licence, visit http://creativecommons.org/licenses/by/4.0/. 
clinical spectrum of COVID-19 ranges from mild to severe, and the mortality rates of patients with severe cases undergoing invasive mechanical ventilation (IMV) are reportedly high [4-6]. Several studies have identified older age as an independent prognostic factor for mortality [4, 7-13]; however, limited information is available on the relationship between mortality and critically ill patients on IMV, stratified by age group $[6,7]$.

In Japan, people aged $>65$ years accounted for $28.7 \%$ of the total population in 2020, and the number of frail elderly individuals has been increasing with advancing age. Moreover, Japan was confronted with a shortage of beds, staff members, and ventilators during the peak of the COVID-19 pandemic. Therefore, the association between age and mortality is an important clinical issue, especially in an aging society, in deciding whether to perform IMV therapy for older adults.

We aimed to investigate the patterns of in-hospital mortality among critically ill patients with COVID-19 who required IMV, by age group, in Japan, while adjusting for other factors related to mortality.

\section{Methods}

\section{Ethics approval}

The present study adhered to the principles of the Declaration of Helsinki and was approved by the ethics committee of the Nippon Medical School Tama Nagayama Hospital. As anonymous data were analysed, the requirement for informed consent was waived.

\section{Settings}

The basic policies of the Ministry of Health, Labour, and Welfare of Japan for the treatment of COVID-19 patients are as follows: all patients with a positive SARS-CoV-2 test result, diagnosed with COVID-19 are admitted to the hospital, while some asymptomatic COVID-19 patients or COVID-19 patients who do not require medical care are isolated either at home or at a designated hotel.

The health system in Japan ensures that the quality of medication use is homogenized, owing to the Japanese universal health insurance coverage system. The insurance system warrants a health check-up at any hospital of the patient's choice, and that the patients are transported to the nearest hospital in an ambulance. All patients fundamentally receive the same healthcare services provided by the health insurance system in all hospitals, although the medical staff decide the treatment strategy considering the patients' age, activity of daily living, medical history, and patients' or their family's intentions when the patients are critically ill and require intensive care.

\section{Study design}

We conducted an observational cohort study using the COVID-19 Registry Japan (COVIREGI-JP) database, a nationwide, multi-centre database created by the National Centre for Global Health and Medicine [14]. The COVIREGI-JP database contains data of hospitalized patients with laboratory-confirmed COVID-19 who were admitted after 1 January 2020, from 925 participating hospitals throughout Japan. These records include information about the patients' age, sex, body mass index (BMI), comorbidities, cause of infection, symptoms, vital signs on admission day, vital signs during hospitalization, treatments, results of laboratory tests, drugs, complications, and outcome at discharge. The follow-up ends at the patients' discharge or death. The study data were collected and managed using REDCap (Research Electronic Data Capture), a secure, web-based data capture application hosted at the Joint Centre for Researchers, Associates, and Clinicians data centre of the National Centre for Global Health and Medicine. Data from the COVIREGIJP database, of the National Centre for Global Health and Medicine, were used for this study with permission.

\section{Participants}

The present study included all COVID-19 patients who were admitted to a hospital and required IMV and were registered in the COVIREGI-JP database from 1 January 2020 to 28 February 2021.

\section{Outcome measures}

The primary outcome was all-cause in-hospital mortality. The secondary outcomes were complications during hospitalization, tracheostomy at discharge, and oxygen therapy at discharge. Complications included bacterial pneumonia, acute respiratory distress syndrome (ARDS), meningitis, ventricular fibrillation, deep venous thrombosis, and pulmonary embolism.

\section{Definition}

We considered the specified time course because the spread and treatment strategy for COVID-19 have been changing drastically over time. Accordingly, we classified the study duration into three periods, in accordance with the epidemic trends of COVID-19 in Japan: the first wave from 1 January 2020 to 31 May 2020, the second wave from 1 June 2020 to 30 September 2020, and the third wave occurred after 1 October 2020.

The actual diagnosis of ARDS was made by each participating doctor in charge in the clinical setting based on the Berlin definition 2012 [15], and the definitions of some variables using logistic regression analysis 
(comorbidity, immunosuppression, drug administration for COVID-19, and drug administration for coagulopathy) are shown in Additional file 1: Table S1.

\section{Statistical analysis}

We stratified the records into 10 each by age group (in 10 -year increments). Continuous values were expressed as mean (standard deviation), and categorical values were expressed as numbers (\%). Since this was an observational study, values were compared using standardized difference [16]. Next, we contrasted survivors with non-survivors in the study group based on the characteristics, treatments, medications, and complications. Further, we performed multiple imputation to decrease the bias caused by incomplete data; each missing value was replaced with a set of five substitute plausible values $[17,18]$. Models were constructed for each imputed dataset, and a single model was created by statistical inference with the results of the five imputed datasets. We performed multiple imputations of covariates via fully conditional specification, including all variables listed in Table 4 and outcomes. Then, we evaluated mortality between age groups using a multivariable regression analysis after adjusting for known potential components and for within-hospital clustering using generalized estimation equation. Treatments and patient care vary between hospitals, even though treatment guidelines for COVID-19 are followed $[19,20]$. Therefore, we considered clustering effect within hospital groups. We selected variables independently associated with COVID-19 mortality for logistic regression analysis, referring to previous studies for clinically important factors [21, 22], and the variables were as follows: sex, steroid use, drug administration for COVID-19, the admission date, BMI $(<30 \mathrm{~kg} /$ $\left.\mathrm{m}^{2}, \geq 30 \mathrm{~kg} / \mathrm{m}^{2}\right)$, fever $\left(<38{ }^{\circ} \mathrm{C}, \geq 38{ }^{\circ} \mathrm{C}\right), \mathrm{SpO} 2<90 \%$, respiratory rate $\geq 30$, Systolic blood pressure $\leq 80 \mathrm{mmHg}$, comorbidities, immunosuppression status, medication use for coagulopathy, ARDS, and days from symptom onset to IMV $[4,7,8,10-13,23]$.

Statistical significance was set at $p<0.05$. All data were analysed using IBM SPSS Statistics version 27 (IBM Corp., Armonk, NY, USA).

\section{Results}

Patient characteristics, vital signs, and symptoms at admission

Of the data obtained from 33,808 cases, the final study population was 1555 (Fig. 1). The mean (standard deviation) age was 64.3 years (12.3) in the survivor group and 73.4 years (9.9) in the non-survivor group. There were $904(80.3 \%)$ males in the survivor group and 306 (76.3\%) in the non-survivor group.

The number of patients who had comorbidities and were immunosuppressed was $842(74.6 \%)$ and 32 (2.9\%), respectively, in the survivor group, and 336 $(83.8 \%)$ and $23(6.0 \%)$, respectively, in the non-survivor group. Fever (over $38{ }^{\circ} \mathrm{C}$ at admission) was reported in $369(32.9 \%)$ patients in the survivor group and 110

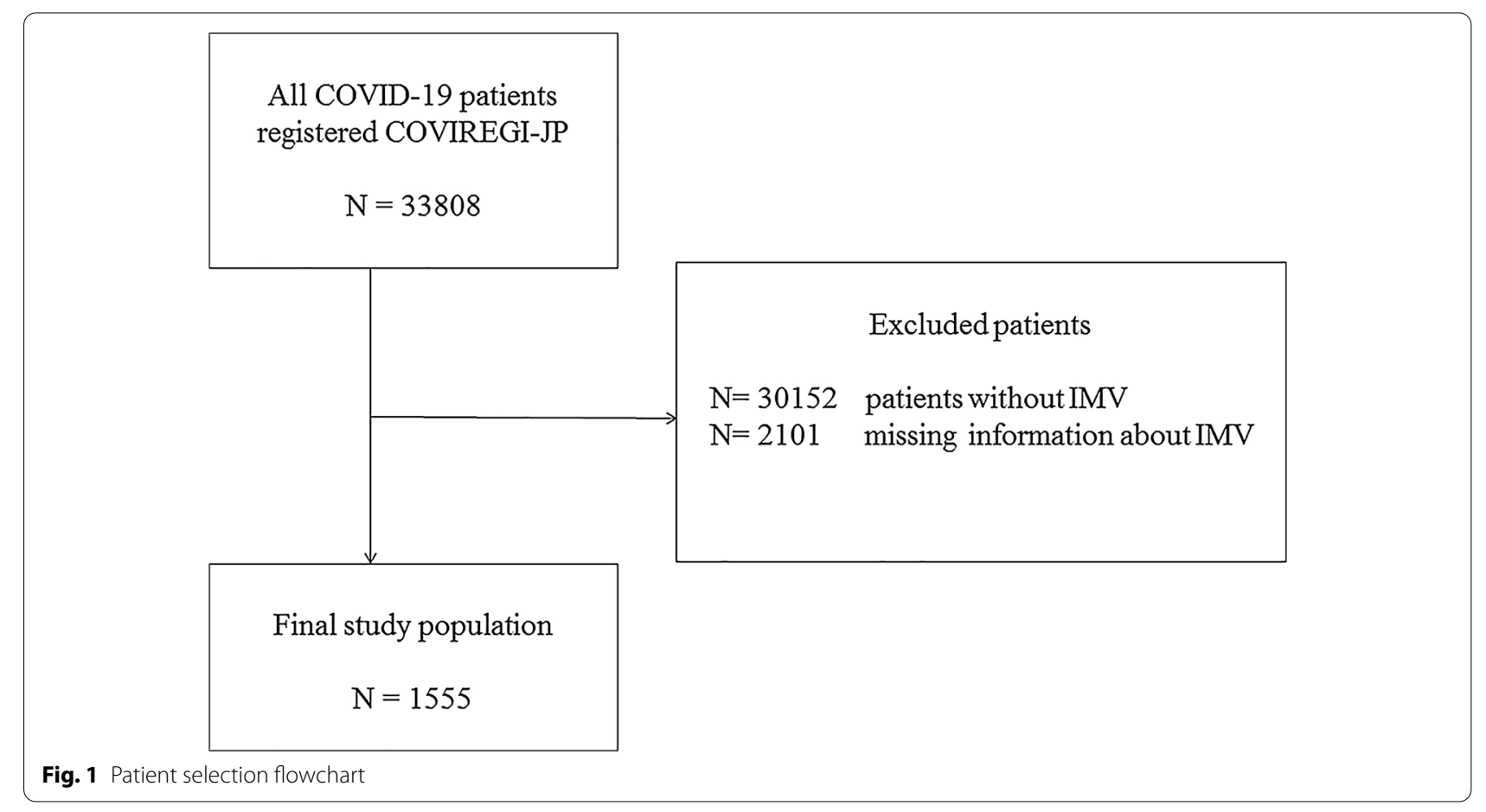


Table 1 Demographic and clinical characteristics of patients with coronavirus disease 2019 under invasive mechanical ventilation therapy

\begin{tabular}{|c|c|c|c|}
\hline Variables & $\begin{array}{l}\text { Survivor } \\
(n=1128)\end{array}$ & $\begin{array}{l}\text { Non-survivor } \\
(n=401)\end{array}$ & $\begin{array}{l}\text { Standardized } \\
\text { difference, \% }\end{array}$ \\
\hline Age, years & $64.3(12.3)$ & $73.4(9.9)$ & -81.5 \\
\hline Male & $904 / 1126(80.3)$ & $306 / 401(76.3)$ & 9.72 \\
\hline Body mass index $\geq 30$ & $157 / 940(16.7)$ & $40 / 314(12.7)$ & 11.31 \\
\hline \multicolumn{4}{|l|}{ Admission date } \\
\hline 3rd wave (October 1st-) & $484 / 1126(43.0)$ & $175 / 401(43.6)$ & -1.21 \\
\hline 2nd wave (June 1st, 2020-September 30, 2020) & 258/1126 (22.9) & $71 / 401(17.7)$ & 12.95 \\
\hline 1st wave (January 26, 2020-May 31, 2020) & $384 / 1126(34.1)$ & $155 / 401(38.7)$ & -9.57 \\
\hline \multicolumn{4}{|l|}{ Race } \\
\hline Japanese & 1091/1120 (97.4) & $391 / 395(99.0)$ & -12.06 \\
\hline Smoking history & $527 / 866(60.9)$ & $177 / 288(61.5)$ & -1.23 \\
\hline Drinking history & $432 / 709(60.9)$ & $121 / 229(52.8)$ & 16.41 \\
\hline Comorbidity & $842 / 1128(74.6)$ & $336 / 401(83.8)$ & -22.81 \\
\hline Hypertension & $552 / 1128(48.9)$ & 193/401 (48.1) & 1.60 \\
\hline Diabetes & $389 / 1128(34.5)$ & 158/401 (39.4) & -10.16 \\
\hline Hyperlipidemia & $256 / 1128(22.7)$ & $97 / 401(24.2)$ & -3.54 \\
\hline Cerebrovascular disease & $97 / 1128(8.6)$ & $54 / 401(13.5)$ & 15.68 \\
\hline COPD & $71 / 1128(6.3)$ & $30 / 401(7.5)$ & -4.74 \\
\hline Bronchial asthma & $63 / 1128(5.6)$ & $19 / 401(4.7)$ & 4.07 \\
\hline Solid tumor & $50 / 1128(4.4)$ & $32 / 401(8.0)$ & -14.97 \\
\hline Liver disease & $46 / 1128(4.1)$ & $22 / 401(5.5)$ & -6.55 \\
\hline Moderate-to-severe chronic kidney disease & $41 / 1128(3.6)$ & 29/401 (7.2) & -15.98 \\
\hline Ischemic heart disease & $41 / 1128(3.6)$ & $26 / 401(6.5)$ & -13.27 \\
\hline Congestive heart failure & $35 / 1128(3.1)$ & $25 / 401(6.2)$ & -14.76 \\
\hline Major neurocognitive disorder & $28 / 1128(2.5)$ & 28/401 (8.3) & -25.88 \\
\hline Chronic lung disease excluding COPD & $28 / 1128(2.5)$ & $26 / 401(6.5)$ & -19.39 \\
\hline Hemodialysis before admission & 28/1128 (3.1) & $22 / 401(5.5)$ & -11.85 \\
\hline Collagen disease & $19 / 1128(1.7)$ & $11 / 401(2.7)$ & -6.82 \\
\hline Metastatic solid tumor & $7 / 1128(0.6)$ & $7 / 401(1.7)$ & -10.33 \\
\hline Lymphoma & $7 / 1128(0.6)$ & $5 / 401(1.2)$ & -6.36 \\
\hline Leukemia & 0/1128(0) & $2 / 401(0.5)$ & -10.33 \\
\hline Immunosuppression & 32/1091 (2.9) & $23 / 384(6.0)$ & 0.01 \\
\hline \multicolumn{4}{|l|}{ Vital signs on admission } \\
\hline AVPU scale A (Alert) & $846 / 1021$ (82.8) & $281 / 366(76.8)$ & 14.99 \\
\hline Fever $\left(\geq 38^{\circ} \mathrm{C}\right)$ & $369 / 1121(32.9)$ & $110 / 397(27.7)$ & 11.33 \\
\hline Respiratory rate $\geq 30$ breaths/ minute & 168/1011 (16.6) & $61 / 359(17.0)$ & -1.07 \\
\hline $\mathrm{SpO} 2<90 \%$ & $163 / 1114(15.1)$ & $71 / 391(18.2)$ & -8.33 \\
\hline Systolic blood pressure $\leq 80 \mathrm{mmHg}$ & 20/1112 (1.8) & 3/396 (0.8) & 8.84 \\
\hline Symptoms at admission & 1088/1102 (98.7) & $378 / 387(97.7)$ & 7.53 \\
\hline
\end{tabular}

Analysis based on records from the COVID-19 Registry Japan. Data given as number of positive observations/total number of observations (percentage) or as mean (standard deviation). For each variable, the number of missing observations can be obtained as the difference between the total number of patients in each phase and the total number of observations

COPD chronic obstructive pulmonary disease, $S D$ standardized difference, IMV invasive mechanical ventilation

For continuous variables, the standardized difference (d) is defined as follows:

$\mathrm{d}=\left(\bar{\chi}_{\text {survivor }}-\bar{\chi}_{\text {non-survivor }}\right) / \sqrt{\left(s^{2} \text { survivor }+s^{2} \text { non }- \text { survivor }\right) / 2}$

For dichotomous variables, the standardized difference is defined as follows:

$\mathrm{d}=\left(\widehat{p}_{\text {survivor }}-\widehat{p}_{\text {non-survivor }}\right) / \sqrt{\{\hat{p} \text { survivor }(1-\hat{p} \text { non }- \text { survivor })+\hat{p} \text { survivor }(1-\hat{p} \text { non }- \text { survivor })\} / 2}$

$\bar{\chi}$ : mean, s: standard deviation, $\widehat{p}$ : proportion 


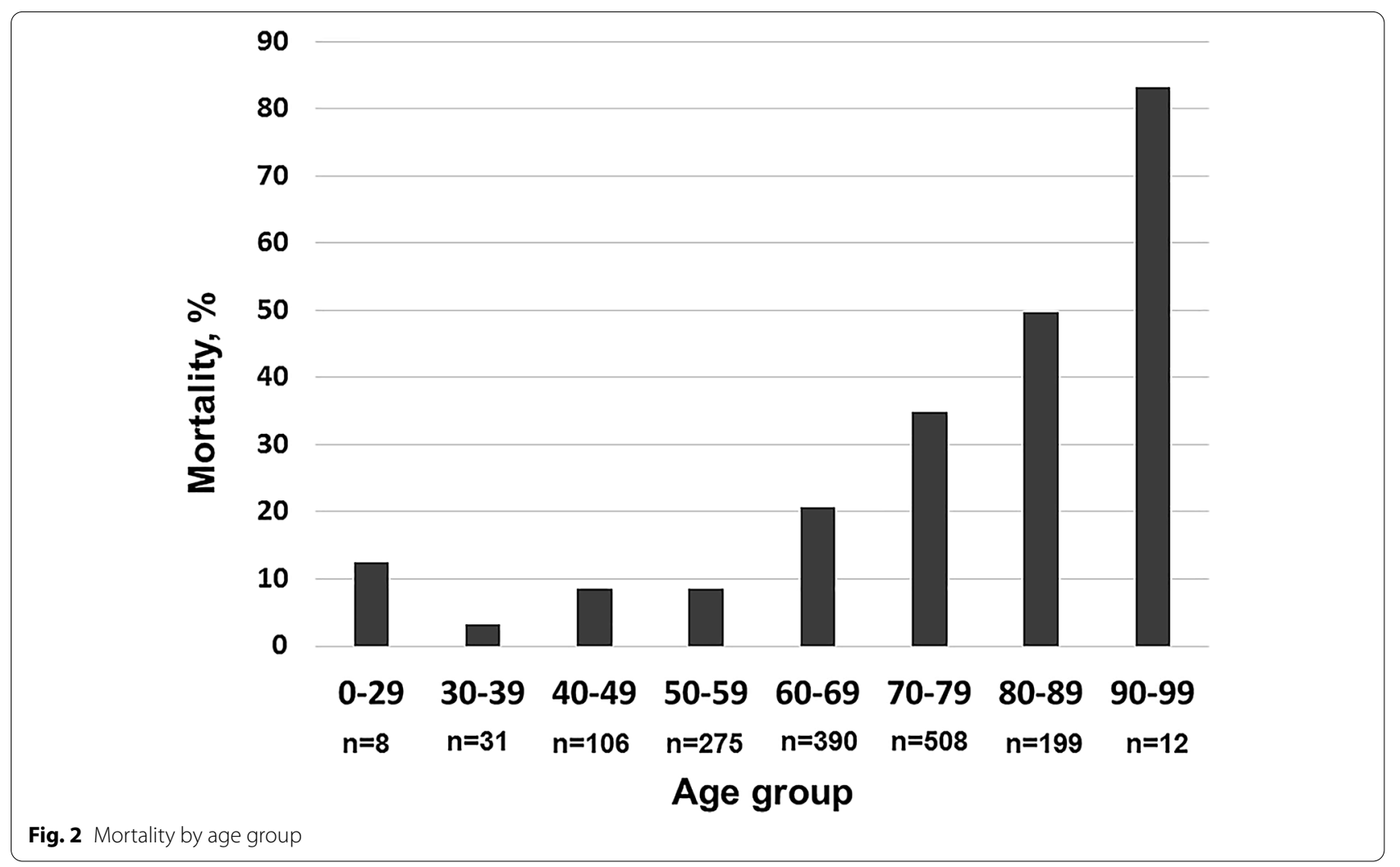

(27.7\%) in the non-survivor group. $\mathrm{SpO}_{2}$ under $90 \%$ at admission was observed in 163 (15.1\%) patients in the survivor group and $71(18.2 \%)$ in the non-survivor group. The number of patients with symptoms at admission was $1,088(98.7 \%)$ in the survivor group and 378 (97.7\%) in the non-survivor group (Table 1). More than $10 \%$ of the data were missing for BMI, smoking history, drinking history, and complication of deep vein thrombosis (Table 1).

\section{Mortality by age group}

The in-hospital mortality rate was 26.3\% (401/1529). When assessed by the age groups, the mortality rate was 8.6\% (24/278), $20.7 \%$ (80/387), 34.9\% (177/507), 49.7\% $(99 / 199)$, and $83.3 \%(10 / 12)$ for patients in their $50 \mathrm{~s}, 60 \mathrm{~s}$, $70 \mathrm{~s}, 80 \mathrm{~s}$, and $90 \mathrm{~s}$, respectively (Fig. 2).

\section{Treatments and complications}

The mean (standard deviation) number of days from symptom onset to IMV therapy was 8.8 days (13.3) for patients who survived and 8.7 days (6.2) for those who died. The mean (standard deviation) duration of IMV therapy was 10.6 days (13.3) for patients who survived and 17.4 days (24.1) for those who died. The percentage of patients who were administered medication for COVID-19 was $89.8 \%$ (1008/1122) among survivors and $89.1 \%$ (353/396) among non-survivors; 69.6\% (767/1102) and $72.2 \%(286 / 396)$ were administered steroids among survivors and non-survivors, respectively (Table 2 ). The prevalence of severe ARDS was $20.4 \%(212 / 1039)$ in the survivor group and $63.3 \%(217 / 343)$ in the non-survivor group. The number of patients who underwent tracheotomy and oxygen therapy at discharge were 116 (10.3\%) and 563 (49.9\%), respectively (Table 3 ).

\section{Multivariable analysis for risk of in-hospital mortality}

The multivariable analysis showed that a 10-year increase in age was significantly associated with mortality (Table 4). The odds ratio of death was 7 times higher in patients in their 70s (OR, 6.92; 95\% confidence interval [CI] 4.23 to $11.31 ; p<0.01), 13$ times higher in patients in their 80s (OR, 13.17; 95\% CI 7.21 to 24.06 ; $p<0.01$ ), and 92 times higher in patients in their 90s (OR, 92.63; 95\% CI 16.66 to 514.98; $p<0.01$ ), compared with those aged $<60$ years. 
Table 2 Treatments of patients with coronavirus disease 2019 under invasive mechanical ventilation therapy

\begin{tabular}{|c|c|c|c|}
\hline Variables & $\begin{array}{l}\text { Survivor } \\
(n=1128)\end{array}$ & $\begin{array}{l}\text { Non-survivor } \\
(n=401)\end{array}$ & $\begin{array}{l}\text { Standardized } \\
\text { difference, \% }\end{array}$ \\
\hline Drug administration for COVID-19 & 1008/1122 (89.8) & $353 / 396(89.1)$ & 2.28 \\
\hline Favipiravir & $545 / 993(54.9)$ & $200 / 349(57.3)$ & -4.84 \\
\hline Remdesivir & 437/987 (44.3) & $127 / 347(36.6)$ & 15.74 \\
\hline Ciclesonide & 231/991 (23.3) & $73 / 347(21.0)$ & 5.54 \\
\hline Nafamostat & 156/964 (16.2) & $66 / 337(19.6)$ & -8.88 \\
\hline Tocilizumab & $123 / 964(12.8)$ & $37 / 337(11.0)$ & 5.56 \\
\hline Hydroxychloroquine & $56 / 991(5.7)$ & $26 / 348(7.5)$ & -7.25 \\
\hline Lopinavir and ritonavir & 50/991 (5.0) & $23 / 347(6.6)$ & -6.85 \\
\hline Ivermectin & $7 / 977(0.7)$ & 2/344 (0.6) & 1.24 \\
\hline Interferon & 3/1007 (0.3) & 2/355 (0.6) & -4.48 \\
\hline Baricitinib & 0/978 (0) & $1 / 344(0.3)$ & -7.76 \\
\hline Antibiotics & $832 / 1103(75.4)$ & 336/393 (85.5) & -25.68 \\
\hline Antifungal agent & $60 / 1105(5.4)$ & $60 / 390(15.4)$ & -33.21 \\
\hline Neuraminidase inhibitor & 12/1099 (1.1) & 10/389 (2.6) & -11.15 \\
\hline Steroid (excluding ciclesonide) & 767/1102 (69.6) & 286/396 (72.2) & -5.73 \\
\hline Drug administration for coagulopathy & $695 / 1066(65.2)$ & $252 / 376(67.0)$ & -3.80 \\
\hline Anticoagulant agents & $655 / 1126(58.2)$ & 239/401 (59.6) & -2.85 \\
\hline Antiplatelet agents & 109/1066 (10.2) & $47 / 376(12.6)$ & -7.56 \\
\hline Thrombolytic agents & $12 / 1068(1.1)$ & $5 / 376(1.3)$ & -1.84 \\
\hline Plasmapheresis & $8 / 1124(0.7)$ & $6 / 399(1.5)$ & -7.68 \\
\hline Immunoglobulin & $57 / 1124(5.1)$ & $43 / 397(10.8)$ & -21.19 \\
\hline Vasopressor/inotropic support & $430 / 1116(38.5)$ & 259/395 (65.6) & -56.36 \\
\hline Renal replacement therapy & $93 / 1117(8.3)$ & $120 / 399(30.1)$ & -57.60 \\
\hline Prone positioning & $344 / 1109(31.0)$ & 142/397 (35.8) & -10.19 \\
\hline High-flow oxygen device use & $222 / 1120(19.8)$ & $88 / 398(22.1)$ & -5.65 \\
\hline Noninvasive positive pressure ventilation & $147 / 1124(13.1)$ & 42/398 (10.6) & 7.74 \\
\hline Duration of symptom onset to IMV, days & $8.8(13.3)$ & $8.7(6.2)$ & 0.96 \\
\hline Duration of IMV, days & $10.6(13.3)$ & $17.4(24.1)$ & -34.9 \\
\hline Re-intubation & 43/1094 (3.9) & 26/396 (6.6) & -12.13 \\
\hline Nitric oxide inhalation & $17 / 1118(1.5)$ & $12 / 399(3.0)$ & -10.13 \\
\hline Neuromuscular blocking agent & $561 / 1067(52.6)$ & $184 / 374(49.2)$ & 6.81 \\
\hline Tracheotomy & $172 / 1119(15.4)$ & $84 / 399(21.1)$ & -14.80 \\
\hline Extracorporeal membrane oxygenation & 106/1127 (9.4) & $45 / 401(11.2)$ & -5.92 \\
\hline
\end{tabular}

Analysis based on records from the COVID-19 Registry Japan. Data given as number of positive observations/total number of observations (percentage) or as mean (standard deviation). For each variable, the number of missing observations can be obtained as the difference between the total number of patients in each phase and the total number of observations

IMV invasive mechanical ventilation, $S D$ standardized difference

For continuous variables, the standardized difference $(d)$ is defined as follows:

$\mathrm{d}=\left(\bar{\chi}_{\text {survivor }}-\bar{\chi}_{\text {non-survivor }}\right) / \sqrt{\left(s^{2} \text { survivor }+s^{2} \text { non }- \text { survivor }\right) / 2}$

For dichotomous variables, the standardized difference is defined as follows:

$\mathrm{d}=\left(\widehat{p}_{\text {survivor }}-\widehat{p}_{\text {non-survivor }}\right) / \sqrt{\{\hat{p} \text { survivor }(1-\hat{p} \text { non }- \text { survivor })+\hat{p} \text { survivor }(1-\hat{p} \text { non }- \text { survivor })\} / 2}$

$\bar{\chi}$ : mean, s: standard deviation, $\widehat{p}$ : proportion

Severe ARDS was associated with high mortality rates (OR, 6.73; 95\% CI 4.50 to 10.04; $p<0.01$ ); however, moderate ARDS and mild ARDS were not related to mortality (OR, 0.63 ; $95 \%$ CI 0.39 to $1.02 ; p=0.06$, OR, $0.54 ; 95 \%$ CI 0.23 to $1.28 ; p=0.16$ ).

\section{Discussion}

This nationwide cohort study assessed the relationship between mortality from COVID-19 and IMV, stratified by age. This study found that mortality drastically increased with increasing age among patients who required mechanical ventilation support. 
Table 3 Outcomes of patients with coronavirus disease 2019 under invasive mechanical ventilation therapy

\begin{tabular}{|c|c|c|c|}
\hline Variables & $\begin{array}{l}\text { Survivor } \\
(n=1128)\end{array}$ & $\begin{array}{l}\text { Non-survivor } \\
(n=401)\end{array}$ & $\begin{array}{l}\text { Standardized } \\
\text { difference, \% }\end{array}$ \\
\hline \multicolumn{4}{|l|}{ Complications } \\
\hline Viral pneumonia (excluding COVID-19) & $39 / 1057(3.5)$ & $24 / 358(6.7)$ & -14.58 \\
\hline Bacterial pneumonia & 290/1051 (27.6) & $180 / 360(50.0)$ & -47.23 \\
\hline \multicolumn{4}{|l|}{ Acute respiratory distress syndrome } \\
\hline None & $460 / 1039(44.3)$ & $88 / 343(25.7)$ & 39.76 \\
\hline Mild & $85 / 1039(8.2)$ & $6 / 343(1.7)$ & 30.31 \\
\hline Moderate & 282/1039 (27.1) & $32 / 343(9.3)$ & 47.41 \\
\hline Severe & $212 / 1039(20.4)$ & $217 / 343(63.3)$ & -96.57 \\
\hline Pleural effusion & 144/1082 (13.3) & $98 / 371(26.4)$ & -33.29 \\
\hline Bacteremia & 79/1093 (7.2) & $71 / 371(19.1)$ & -35.77 \\
\hline Deep vein thrombosis & $61 / 995(6.1)$ & 19/326 (5.8) & 1.27 \\
\hline Pneumothorax & 33/1093 (3.0) & $51 / 380(13.4)$ & -38.61 \\
\hline Hemoptysis & $31 / 1050(3.0)$ & $34 / 361(9.4)$ & -26.78 \\
\hline Ventricular defibrillation, ventricular tachycardia & 28/1097 (2.6) & $30 / 376(8.0)$ & -24.28 \\
\hline Gastrointestinal bleeding & 23/1094 (2.1) & $46 / 379(12.1)$ & -39.70 \\
\hline Seizures & 21/1101 (1.9) & $5 / 381(1.3)$ & 4.78 \\
\hline Cerebral infarction, cerebral hemorrhage & 20/1104 (1.8) & $21 / 372(5.6)$ & -20.23 \\
\hline Pulmonary embolism & 20/1022 (2.0) & $14 / 335(4.2)$ & -12.72 \\
\hline Ischemic heart disease & 18/1098 (1.6) & $8 / 374(2.1)$ & -3.71 \\
\hline Myocarditis, pericarditis, cardiomyopathy & 10/1100 (0.9) & $4 / 373(1.1)$ & -2.01 \\
\hline Meningitis, encephalitis & $7 / 1075(0.7)$ & $2 / 363(0.6)$ & 1.24 \\
\hline Endocarditis & $4 / 1065(0.4)$ & $1 / 359(0.3)$ & 1.69 \\
\hline Tracheotomy at discharge & $116 / 1128(10.3)$ & & \\
\hline Oxygen therapy at discharge & $563 / 1128(49.9)$ & & \\
\hline
\end{tabular}

Analysis based on records from the COVID-19 Registry Japan. Data given as number of positive observations/total number of observations (percentage). For each variable, the number of missing observations can be obtained as the difference between the total number of patients in each phase and the total number of observations

For continuous variables, the standardized difference $(d)$ is defined as follows:

$\mathrm{d}=\left(\bar{\chi}_{\text {survivor }}-\bar{\chi}_{\text {non-survivor }}\right) / \sqrt{\left(s^{2} \text { survivor }+s^{2} \text { non }- \text { survivor }\right) / 2}$

For dichotomous variables, the standardized difference is defined as follows:

$\mathrm{d}=\left(\widehat{p}_{\text {survivor }}-\widehat{p}_{\text {non-survivor }}\right) / \sqrt{\{\hat{p} \text { survivor }(1-\hat{p} \text { non }- \text { survivor })+\hat{p} \text { survivor }(1-\hat{p} \text { non }- \text { survivor })\} / 2}$

$\bar{\chi}$ : mean, s: standard deviation, $\widehat{p}$ : proportion

The current study precisely reported mortality in COVID-19 patients who underwent IMV, which is the most critically ill group, in a large population. Although some studies have reported findings on critically ill patients with COVID-19, only a few large-sample surveys have focused on patients undergoing IMV, which is one of the most important treatment options for pneumonia and respiratory illness $[4-7,11,12]$. Therefore, this study may be valuable in understanding the epidemiology of severe respiratory dysfunction caused by COVID-19.

The results of our study demonstrated that increasing age was firmly associated with a higher risk of mortality in COVID-19 patients undergoing IMV. Although previous studies have reported the risk of advanced age, the current study suggested that age was associated with a higher risk in comparison to other factors, and that preventing progression to severe COVID-19 in elderly patients may be a great public health issue. Vaccination, careful observation for asymptomatic patients with COVID-19, and early treatment for symptomatic patients with COVID-19 may be strongly recommended for the people aged $>60$ years.

This study also indicated other features of severe COVID-19. The definition of ARDS as a COVID-19 complication adopted in this study was based on the Berlin definition 2012; respiratory failure occurred within 1 week of known clinical insult or new or worsening respiratory symptoms (Additional file 1: Table S1) [15]. ARDS was not diagnosed in $44.3 \%$ of survivors and $25.7 \%$ of non-survivors, and the mean duration from symptom onset to IMV therapy was about 9 days in both groups. These results suggested that several patients struggling 
Table 4 Multiple logistic regression analysis of in-hospital mortality risk among coronavirus disease 2019 patients on mechanical ventilation after adjusting for within-hospital clustering

\begin{tabular}{|c|c|c|c|}
\hline \multirow[t]{2}{*}{ Variable } & \multicolumn{3}{|c|}{ After multiple imputation } \\
\hline & Odds ratio & $95 \% \mathrm{Cl}$ & $p$-value \\
\hline Age $\geq 90$ & 92.63 & $16.66-514.98$ & $<0.01$ \\
\hline $80-89$ & 13.17 & $7.21-24.06$ & $<0.01$ \\
\hline $70-79$ & 6.92 & $4.23-11.31$ & $<0.01$ \\
\hline $60-69$ & 2.60 & $1.65-4.08$ & $<0.01$ \\
\hline $59 \leq$ (reference) & 1 & & \\
\hline Male & 1.04 & $0.74-1.46$ & 0.82 \\
\hline Body mass index $\geq 30 \mathrm{~kg} / \mathrm{m}^{2}$ & 1.37 & $0.91-2.07$ & 0.14 \\
\hline Smoking history & 1.16 & $0.80-1.68$ & 0.44 \\
\hline Comorbidity & 1.33 & $0.87-2.03$ & 0.19 \\
\hline Immunosuppression & 2.17 & $1.14-4.12$ & 0.02 \\
\hline \multicolumn{4}{|l|}{ Admission date } \\
\hline 3rd wave & 0.86 & $0.59-1.26$ & 0.45 \\
\hline 2nd wave & 0.62 & $0.41-0.95$ & 0.03 \\
\hline 1st wave (reference) & 1 & & \\
\hline \multicolumn{4}{|l|}{ Vital signs on admission } \\
\hline Fever $\left(\geq 38^{\circ} \mathrm{C}\right)$ & 0.83 & $0.61-1.13$ & 0.25 \\
\hline $\mathrm{SpO} 2<90 \%$ & 1.00 & $0.68-1.46$ & 0.99 \\
\hline Respiratory rate $\geq 30$ & 1.02 & $0.70-1.50$ & 0.90 \\
\hline $\begin{array}{l}\text { Systolic blood pres- } \\
\text { sure } \leq 80 \mathrm{mmHg}\end{array}$ & 0.25 & $0.07-0.96$ & 0.04 \\
\hline \multicolumn{4}{|l|}{ ARDS } \\
\hline Severe & 6.73 & $4.50-10.04$ & $<0.01$ \\
\hline Moderate & 0.63 & $0.39-1.02$ & 0.06 \\
\hline Mild & 0.54 & $0.23-1.28$ & 0.16 \\
\hline None (reference) & 1 & & \\
\hline Drug administration for COVID-19 & 0.97 & $0.56-1.67$ & 0.90 \\
\hline Steroid use & 1.26 & $0.84-1.88$ & 0.26 \\
\hline $\begin{array}{l}\text { Drug administration for coagu- } \\
\text { lopathy }\end{array}$ & 0.96 & $0.68-1.35$ & 0.82 \\
\hline Days from symptom onset to IMV & 1.00 & $1.00-1.01$ & 0.47 \\
\hline
\end{tabular}

Analysis based on records from the COVID-19 Registry Japan

$A R D S$ acute respiratory distress syndrome, IMV invasive mechanical ventilation

with severe COVID-19 showed gradual deterioration over a 1-week period, and required IMV therapy. However, multivariable analysis showed that severe ARDS was associated with high risk of mortality; that is, acute deterioration in COVID-19 patients might be a sign of worse outcome.

The strength of this study is its design, as it is a nationwide, multi-centre survey in Japan. Initially, we demonstrated some features of the Japanese medical system. As the Japanese health insurance system supports homogenizing and generalizing the Japanese medical system, the outcome of this study was the result of uniformed standard medical treatment, including IMV support, for all ages. In the present Japanese super-aging society, our study revealed that older age had a great effect on mortality associated with IMV therapy in COVID-19 patients, after adjusting for important variables that are independently associated with mortality. This result may be helpful in developing effective therapeutic strategies against COVID-19.

There are some limitations to the current study. First, Dawn et al., reported that high demand for the intensive care unit services and workload have an effect on mortality [24], and a similar situation was observed in Japan during the study period. In addition, the size of the hospitals that participated in the current study varied. Second, this database did not include information about the strain of COVID-19; therefore, we could not adjust for the effect of the COVID-19 strain on mortality. To reduce the effect of these two factors, we adjusted for hospital clustering and time course. Third, these results may not be generalizable to other countries where the medical and social systems are different from those in Japan. Fourth, the occurrence of the primary outcome might influence/preclude the occurrence of secondary outcomes (complications, tracheostomy, or oxygen therapy at discharge). However, we could not evaluate the cause of death in the current study. Thus, we could not evaluate the cause-effect relationship between the primary and secondary outcomes. Finally, the diagnosis of complications was made by each doctor in charge in the clinical setting. There might be a possibility of misdiagnosis because of these factors.

\section{Conclusion}

The findings of this multi-centre, observational study, which assessed COVID-19 patients in Japan, demonstrated that age was a crucial prognostic factor in identifying patients at risk of dying among critically ill COVID-19 patients who required IMV. Further largescale, prospective studies are required to validate our results.

\section{Abbreviations}

COVID-19: Coronavirus disease 2019; IMV: Invasive mechanical ventilation; ARDS: Acute respiratory distress syndrome; BMI: Body mass index; COVIREGI-JP: COVID-19 Registry Japan; Cl: Confidence interval.

\section{Supplementary Information}

The online version contains supplementary material available at https://doi. org/10.1186/s13613-021-00959-6.

Additional file 1: Table S1. Definition of the variables for confounding factors using multivariable analysis in Table 4. 


\section{Acknowledgements \\ Not applicable.}

\section{Authors' contributions}

All authors contributed to the write-up of this manuscript. CT analysed the data and contributed to writing of the manuscript. TT oversaw the analysis and interpretation. FN, SK, AT, JK, YI, YI, SS, AS, MK and KU were responsible for the data interpretation. MH, TM, YA, SS and NO performed the data collection. All authors read and approved the final manuscript.

\section{Funding}

None.

\section{Availability of data and materials}

The data that support the findings of this study are available from the corresponding author upon reasonable request.

\section{Declarations}

\section{Ethics approval and consent to participate}

The ethics committee of the Nippon Medical School Tama Nagayama Hospital approved this study. Written informed consent was waived because our analysis did not include personal identifying information.

\section{Consent for publication}

Not applicable.

\section{Competing interests}

The authors declare that they have no competing interests.

\section{Author details}

${ }^{1}$ Department of Emergency and Critical Care Medicine, Nippon Medical School Tama Nagayama Hospital, Tama-shi, Tokyo 2068512, Japan. ${ }^{2}$ Department of Emergency and Critical Care Medicine, Nippon Medical School Musashikosugi Hospital, 1-396 Kosugimachi, Nakahara-ku, Kawasaki, Kanagawa 211-8533, Japan. ${ }^{3}$ Department of Clinical Epidemiology and Health Economics, School of Public Health, The University of Tokyo, Bunkyo, Tokyo 1138654, Japan. ${ }^{4}$ Disease Control and Prevention Center, National Center for Global Health and Medicine, Shinjuku, Tokyo 1628655, Japan. ${ }^{5}$ AMR Clinical Reference Center, National Center for Global Health and Medicine, Shinjuku, Tokyo 1628655, Japan. ${ }^{6}$ Department of Epidemiology and Prevention, Center for Clinical Sciences, National Center for Global Health and Medicine, Shinjuku, Tokyo 1628655, Japan. ${ }^{7}$ Department of Respiratory Medicine, National Center for Global Health and Medicine, Shinjuku, Tokyo 1628655, Japan.

Received: 9 Auqust 2021 Accepted: 22 November 2021 Published online: 11 December 2021

\section{References}

1. Zhu N, Zhang D, Wang W, Li X, Yang B, Song J, Zhao X, Huang B, Shi W, Lu R, et al. A novel coronavirus from patients with pneumonia in China, 2019. N Engl J Med. 2020;382(8):727-33.

2. Coronavirus disease (COVID-19) outbreak, 2020. https://www.who.int/ emergencies/diseases/novel-coronavirus-2019/events-as-they-happen.

3. Current status of the novel coronavirus infection and the response of the MHLW. https://www.mhlw.go.jp/stf/nepage_/09290.html.

4. Xie J, Wu W, Li S, Hu Y, Hu M, Li J, Yang Y, Huang T, Zheng K, Wang Y, et al. Clinical characteristics and outcomes of critically ill patients with novel coronavirus infectious disease (COVID-19) in China: a retrospective multicenter study. Intensive Care Med. 2020;46(10):1863-72.

5. Arentz M, Yim E, Klaff L, Lokhandwala S, Riedo FX, Chong M, Lee M. Characteristics and outcomes of 21 critically ill patients with COVID-19 in Washington State. JAMA. 2020;323(16):1612-4.

6. Suleyman G, Fadel RA, Malette KM, Hammond C, Abdulla H, Entz A, Demertzis Z, Hanna Z, Failla A, Dagher C, et al. Clinical characteristics and morbidity associated with coronavirus disease 2019 in a series of patients in metropolitan detroit. JAMA Netw Open. 2020;3(6):e2012270.
7. Ioannou GN, Locke E, Green P, Berry K, O'Hare AM, Shah JA, Crothers K, Eastment MC, Dominitz JA, Fan VS. Risk factors for hospitalization, mechanical ventilation, or death among 10131 US veterans with SARSCoV-2 infection. JAMA Netw Open. 2020;3(9):e2022310.

8. Wu C, Chen X, Cai Y, Xia J, Zhou X, Xu S, Huang H, Zhang L, Zhou X, Du C, et al. Risk factors associated with acute respiratory distress syndrome and death in patients with coronavirus disease 2019 pneumonia in Wuhan, China. JAMA Intern Med. 2020;180(7):934-43.

9. Richardson S, Hirsch JS, Narasimhan M, Crawford JM, McGinn T, Davidson KW, the Northwell C-RC, Barnaby DP, Becker LB, Chelico JD, et al. Presenting characteristics, comorbidities, and outcomes among 5700 patients hospitalized with COVID-19 in the New York City Area. JAMA. 2020;323(20):2052-9.

10. Rosenthal N, Cao Z, Gundrum J, Sianis J, Safo S. Risk factors associated with in-hospital mortality in a US national sample of patients with COVID19. JAMA Netw Open. 2020;3(12):e2029058.

11. Grasselli G, Greco M, Zanella A, Albano G, Antonelli M, Bellani G, Bonanomi E, Cabrini L, Carlesso E, Castelli G, et al. Risk factors associated with mortality among patients with covid-19 in intensive care units in Lombardy, Italy. JAMA Intern Med. 2020;180(10):1345-55.

12. Gupta S, Hayek SS, Wang W, Chan L, Mathews KS, Melamed ML, Brenner SK, Leonberg-Yoo A, Schenck EJ, Radbel J, et al. Factors associated with death in critically ill patients with coronavirus disease 2019 in the US. JAMA Intern Med. 2020;180:1436-46.

13. Nguyen NT, Chinn J, Nahmias J, Yuen S, Kirby KA, Hohmann S, Amin A. Outcomes and mortality among adults hospitalized with COVID-19 at US Medical Centers. JAMA Netw Open. 2021;4(3):e210417.

14. Matsunaga N, Hayakawa K, Terada M, Ohtsu H, Asai Y, Tsuzuki S, Suzuki S, Toyoda A, Suzuki K, Endo M, et al. Clinical epidemiology of hospitalized patients with COVID-19 in Japan: report of the COVID-19 REGISTRY JAPAN. Clin Infect Dis. 2020. https://doi.org/10.1093/cid/ciaa1470.

15. Force ADT, Ranieri VM, Rubenfeld GD, Thompson BT, Ferguson ND, Caldwell E, Fan E, Camporota L, Slutsky AS. Acute respiratory distress syndrome: the Berlin Definition. JAMA. 2012;307(23):2526-33.

16. Austin PC. Balance diagnostics for comparing the distribution of baseline covariates between treatment groups in propensity-score matched samples. Stat Med. 2009;28(25):3083-107.

17. Little RJ, D'Agostino R, Cohen ML, Dickersin K, Emerson SS, Farrar JT, Frangakis C, Hogan JW, Molenberghs G, Murphy SA, Neaton JD, et al. The prevention and treatment of missing data in clinical trials. $\mathrm{N}$ Engl J Med. 2012;367:1355-60.

18. Janssen KJ, Donders AR, Harrell FE Jr, Vergouwe Y, Chen Q, Grobbee DE, Moons KG. Missing covariate data in medical research: to impute is better than to ignore. J Clin Epidemiol. 2010;63(7):721-7.

19. Alhazzani W, Møller MH, Arabi YM, Loeb M, Gong MN, Fan E, Oczkowski S, Levy MM, Derde L, Dzierba A, et al. Surviving sepsis campaign: guidelines on the management of critically ill adults with coronavirus disease 2019 (COVID-19). Crit Care Med. 2020;48(6):e440-69.

20. Kazuma Y, Ryo Y, Go I, Hideki H, Takero T, Yoshitaka H. Japanese Rapid/Living recommendations on drug management for COVID-19. Acute Med Surg 2021, 2021(May 15).

21. Steyerberg E. Stepwise selection in small data sets a simulation study of bias in logistic regression analysis. J Clin Epidemiol. 1999;52(10):935-42.

22. Steyerberg EW, Eijkemans MJC, Van Houwelingen JC, Lee KL, Habbema JDF. Prognostic models based on literature and individual patient data in logistic regression analysis. Stat Med. 2000;19(2):141-60.

23. Group RC, Horby P, Lim WS, Emberson JR, Mafham M, Bell JL, Linsell L, Staplin N, Brightling C, Ustianowski A, et al. Dexamethasone in Hospitalized Patients with Covid-19. N Engl J Med. 2021;384(8):693-704.

24. Bravata DM, Perkins AJ, Myers LJ, Arling G, Zhang Y, Zillich AJ, Reese L, Dysangco A, Agarwal R, Myers J, et al. Association of intensive care unit patient load and demand with mortality rates in US department of veterans affairs hospitals during the COVID-19 pandemic. JAMA Netw Open. 2021;4(1):e2034266

\section{Publisher's Note}

Springer Nature remains neutral with regard to jurisdictional claims in published maps and institutional affiliations. 